\title{
Research on the Solid Solution Behavior of Titanium Inclusion for the High Strength Tire Cord Steel
}

\author{
Jialiu Lei ${ }^{*}$, Dongnan Zhao1, Yuedong Jiang2 \\ ${ }^{1}$ Metallurgy Engineering Department, School of Materials Science and Engineering, Hubei Polytechnic University, Huangshi, \\ China \\ ${ }^{2}$ Research and Development Center of Wuhan Iron \& Steel Group, Wuhan, China \\ Email: * wkd15827525243@163.com
}

How to cite this paper: Lei, J.L., Zhao, D.N. and Jiang, Y.D. (2018) Research on the Solid Solution Behavior of Titanium Inclusion for the High Strength Tire Cord Steel. Journal of Surface Engineered Materials and Advanced Technology, 8, 49-57. https://doi.org/10.4236/jsemat.2018.83005

Received: May 21, 2018

Accepted: July 2, 2018

Published: July 6, 2018

Copyright ( $\odot 2018$ by authors and Scientific Research Publishing Inc. This work is licensed under the Creative Commons Attribution International License (CC BY 4.0).

http://creativecommons.org/licenses/by/4.0/

\begin{abstract}
In order to improve the quality of the cord steel wire rod and achieve the effective control of titanium inclusion, the solid solution behavior of titanium inclusion in tire cord steel during the heating process was discussed in this paper, through the thermodynamic theory analysis, combined with the CLSM experiment. The conclusions are as follows: 1) According to the law of Ostwald repening, the coarsening rate of titanium carbonitride inclusion is very small, the coarsening behavior of titanium carbonitride inclusion cannot be considered in the heating and holding stage. 2) The solid solution behavior of titanium inclusion in the heating process is obviously existed. 3) Through the proper control of rolling temperature, holding time and the subsequent cooling rate, the size and quantity of large particle titanium inclusion in the high strength tire cord steel can be effectively controlled.
\end{abstract}

\section{Keywords}

Tire Cord Steel, Titanium Inclusion, Ostwald, Solid Solution, CLSM

\section{Introduction}

The steel cord is the most ideal material for radial tire. It has special technical requirements in every process [1]. While the high-hardness brittle titanium inclusion $\operatorname{Ti}\left(\mathrm{C}_{x} \mathrm{~N}_{1-x}\right)$, it seriously affects the quality of the steel cord [2] [3], so it is the main cause of fatigue deterioration [4]. In recent years, the strength level of the cord steel wire rod is continuously increased. As the purity of molten steel is improved significantly, the oxide inclusions are well controlled. Then the hazard 
of titanium inclusion is more outstanding. The control of high-hardness brittle titanium inclusion is one of the major challenges in the smelting process [5] [6]. At the same time, in order to adapt to the low-carbon metallurgy and energy saving environment, the users adopted the technology to reduce an intermediate heat treatment and change the oil quenching to water quenching. Thus, higher requirements are put forward on the titanium inclusions for the cord steel wire rod. Although via the refining technology the content of Ti and $\mathrm{N}$ can be controlled in a low range, but the properties of titanium inclusions can not be improved through effective smelting technology.

China is a major producer of tire cord steel, but the production of high strength level tire cord steel still has a big difference compared with abroad [7] [8]. Therefore, the solid solution behavior and influence mechanism of titanium inclusion based on the thermodynamic theory analysis, and CLSM experiment for the tire cord steel were studied in the heating process. These have an important guiding significance to the control of the size and quantity of large particle titanium inclusions, and the realization of the efficient production for the high strength tire cord steel.

\section{Solid Solution Thermodynamics of $\operatorname{Ti}\left(\mathrm{C}_{x} \mathrm{~N}_{1-x}\right)$}

As the tire cod steel is a high carbon steel, the $\mathrm{TiN}$ and $\mathrm{TiC}$ inclusion can be inter-miscible simultaneously, while the crystal structure of $\mathrm{TiN}$ and $\mathrm{TiC}$ are the same, So they can form $\operatorname{Ti}\left(\mathrm{C}_{x} \mathrm{~N}_{1-x}\right)$ with each other. The solid solution reaction in austenite can be expressed as [9]:

$$
\begin{gathered}
\operatorname{Ti}\left(\mathrm{C}_{x} \mathrm{~N}_{1-x}\right)=x \mathrm{TiC}+(1-x) \mathrm{TiN} \\
K_{a}=\frac{[\mathrm{TiC}]^{x} \cdot[\mathrm{TiN}]^{1-x}}{\operatorname{Ti}\left(\mathrm{C}_{x} \mathrm{~N}_{1-x}\right)}=x^{x} \cdot(1-x)^{1-x} \\
x \mathrm{TiC}=x[\mathrm{Ti}]_{\gamma}+x[\mathrm{C}]_{\gamma} \\
K_{b}=\frac{\left(w[\mathrm{Ti}]_{\gamma}\right)^{x} \cdot\left(w[\mathrm{C}]_{\gamma}\right)^{x}}{[\mathrm{TiC}]^{x}}=\frac{\left(w[\mathrm{Ti}]_{\gamma}\right)^{x} \cdot\left(w[\mathrm{C}]_{\gamma}\right)^{x}}{x^{x}} \\
K_{c}=\frac{(1-x) \mathrm{TiN}=(1-x)[\mathrm{Ti}]_{\gamma}+(1-x)[\mathrm{N}]_{\gamma}}{\left.(\mathrm{Ti}]_{\gamma}\right)^{1-x} \cdot\left(w[\mathrm{~N}]_{\gamma}\right)^{1-x}}=\frac{\left(w[\mathrm{Ti}]_{\gamma}\right)^{1-x} \cdot\left(w[\mathrm{NiN}]_{\gamma}\right)^{1-x}}{(1-x)^{1-x}}
\end{gathered}
$$

The solid solubility product formula of $\mathrm{TiC}$ and $\mathrm{TiN}$ still can be used in $\operatorname{Ti}\left(\mathrm{C}_{X} \mathrm{~N}_{1-x}\right)[10]$ :

$$
\begin{gathered}
K_{b}=\left(K_{\mathrm{TiC}}\right)^{x}=\left\{\frac{w[\mathrm{Ti}]_{\gamma} \cdot w[\mathrm{C}]_{\gamma}}{x}\right\}^{x} \\
K_{c}=\left(K_{\mathrm{TiN}}\right)^{1-x}=\left\{\frac{w[\mathrm{Ti}]_{\gamma} \cdot w[\mathrm{~N}]_{\gamma}}{1-x}\right\}^{1-x}
\end{gathered}
$$


In formula (7) and (8), $K_{\mathrm{TiN}}$ and $K_{\mathrm{TiC}}$ are the equilibrium constant when TiN and $\mathrm{TiC}$ precipitated. $x$ represents the mole fraction of $\mathrm{TiC}$ phase in $\operatorname{Ti}\left(\mathrm{C}_{x} \mathrm{~N}_{1-x}\right)$. The initial content of elements $\mathrm{C}, \mathrm{N}$ and $\mathrm{Ti}$ in the tire cord steel are represented by $w[\mathrm{C}]_{0}, w[\mathrm{~N}]_{0}$ and $w[\mathrm{Ti}]_{0}$ respectively. Then according to the formula of solid solubility product and the ideal ratio relationship of each element in $\operatorname{Ti}\left(\mathrm{C}_{x} \mathrm{~N}_{1-x}\right)$, the following formulas can be acquired:

$$
\begin{gathered}
\lg \frac{w[\mathrm{Ti}]_{\gamma} \cdot w[\mathrm{~N}]_{\gamma}}{1-x}=\lg K_{\mathrm{TiN}}=0.32-\frac{8000}{T} \\
\lg \frac{w[\mathrm{Ti}]_{\gamma} \cdot w[\mathrm{C}]_{\gamma}}{x}=\lg K_{\mathrm{TiC}}=2.75-\frac{7000}{T} \\
\frac{w[\mathrm{Ti}]_{0}-w[\mathrm{Ti}]_{\gamma}}{w[\mathrm{C}]_{0}-w[\mathrm{C}]_{\gamma}}=\frac{\mathrm{A}_{\mathrm{Ti}}}{x \mathrm{~A}_{\mathrm{C}}}=\frac{48}{12 x} \\
\frac{w[\mathrm{Ti}]_{0}-w[\mathrm{Ti}]_{\gamma}}{w[\mathrm{~N}]_{0}-w[\mathrm{~N}]_{\gamma}}=\frac{\mathrm{A}_{\mathrm{Ti}}}{(1-x) \mathrm{A}_{\mathrm{N}}}=\frac{48}{14(1-x)}
\end{gathered}
$$

In formula (11) and (12), $\mathrm{A}_{\mathrm{C}}, \mathrm{A}_{\mathrm{N}}$ and $\mathrm{A}_{\mathrm{Ti}}$ are the relative atomic mass of element $\mathrm{C}, \mathrm{N}$ and Ti respectively. According to the above formulas, the equilibrium solution of $\mathrm{C}, \mathrm{N}, \mathrm{Ti}$ in the austenite and the value of $x$ can be calculated under a certain temperature.

When $w[\mathrm{C}]_{\gamma}=w[\mathrm{C}]_{0}, w[\mathrm{~N}]_{\gamma}=w[\mathrm{~N}]_{0}, w[\mathrm{Ti}]_{\gamma}=w[\mathrm{Ti}]_{0}$, the $\operatorname{Ti}\left(\mathrm{C}_{x} \mathrm{~N}_{1-x}\right)$ is solid solution completely. Then according to the formula (9) and (10), the following formulas can be acquired:

$$
w[\mathrm{Ti}]_{\gamma} \cdot\left(\frac{w[\mathrm{C}]_{\gamma}}{10^{2.75-7000 / T}}+\frac{w[\mathrm{~N}]_{\gamma}}{10^{0.32-8000 / T}}\right)=1
$$

Then the temperature $T$ can be calculated according to the formula (13). When the temperature is higher than $T$, the $\operatorname{Ti}\left(\mathrm{C}_{x} \mathrm{~N}_{1-x}\right)$ have the thermodynamic conditions of solid solution.

\section{Ostwald Ripening of $\operatorname{Ti}\left(\mathrm{C}_{x} \mathrm{~N}_{1-x}\right)$ and Solid Solution Characteristics}

During the process of steel rolling, the size and quantity of titanium inclusions will be changed to a certain extent. For the titanium inclusions, according to the Ostwald ripening, there existed the concentration gradient between the small and large particles. The $\mathrm{Ti}$ and $\mathrm{N}$ of small particles will diffuse to the large particles. The diffusion result is that, the small particles become smaller and even disappeared, while the large titanium inclusions will be coarsened and grow up [11].

The coarsening rate of large particle $\mathrm{Ti}\left(\mathrm{C}_{x} \mathrm{~N}_{1-x}\right)$ inclusion in the heating process can be calculated by Ostwald ripening rule [12]:

$$
d_{t}^{3}=d_{0}^{3}+\frac{64 D \sigma V_{\mathrm{MNC}}^{2} C_{0}}{9 R T V_{m} C_{p}} t=d_{0}^{3}+m^{3} t
$$




$$
m=\left(\frac{64 D \sigma V_{\mathrm{MNC}}^{2} C_{0}}{9 R T V_{m} C_{p}}\right)^{1 / 3}
$$

In the above equation, $d_{t}$ and $d_{0}$ are the average size of $\operatorname{Ti}\left(\mathrm{C}_{x} \mathrm{~N}_{1-x}\right)$ at time $t$ and initial time. $D$ is the diffusion coefficient of restrictive elements in austenite. $\sigma$ is the semi-coherent grain boundary energy between $\operatorname{Ti}\left(\mathrm{C}_{X} \mathrm{~N}_{1-x}\right)$ and $\gamma \cdot V_{\text {MNC }}$ and $V_{m}$ are the molar volumes of $\mathrm{Ti}\left(\mathrm{C}_{x} \mathrm{~N}_{1-x}\right)$ and $\mathrm{Ti}$ atom respectively. $C_{0}$ and $C_{p}$ are the balanced atomic concentrations in the austenite and $\operatorname{Ti}\left(\mathrm{C}_{x} \mathrm{~N}_{1-x}\right)$ phases respectively. $m$ is the coarsening rate coefficient of $\operatorname{Ti}\left(\mathrm{C}_{x} \mathrm{~N}_{1-x}\right)$.

When $m t^{1 / 3}$ is very small, $d_{t} \approx d_{0}$, the coarse behavior of titanium inclusions can be ignored. As for $\operatorname{Ti}\left(\mathrm{C}_{x} \mathrm{~N}_{1-x}\right), \mathrm{Ti}$ is the restrictive element. The diffusion coefficient of $\mathrm{Ti}$ in austenite is [13]:

$$
D=0.15 \exp \left(-\frac{251000}{R T}\right) \mathrm{cm}^{2} / \mathrm{s}
$$

At the temperature of $1100^{\circ} \mathrm{C}$, the molar volume of Ti is $1.092 \times 10^{-5} \mathrm{~m}^{3} / \mathrm{mol}$, the molar volume of TiC and TiN are $1.243 \times 10^{-5} \mathrm{~m}^{3} / \mathrm{mol}$ and $1.182 \times 10^{-5}$ $\mathrm{m}^{3} / \mathrm{mol}$ [14]. The molar volume of $\operatorname{Ti}\left(\mathrm{C}_{x} \mathrm{~N}_{1-x}\right)$ can be obtained by linear interpolation, according to the mole ratio of $x$ and the molar volume of TiC and TiN. In equilibrium, the atomic concentration of $\operatorname{Ti}\left(C_{p}\right)$ in $\operatorname{Ti}\left(\mathrm{C}_{x} \mathrm{~N}_{1-x}\right)$ is 1 , and the atomic concentration in the matrix $\left(C_{0}\right)$ can be calculated according to its balanced solid solubility $w[\mathrm{Ti}]$.

$$
C_{0}=\frac{w[\mathrm{Ti}]_{\gamma} \mathrm{A}_{\mathrm{Fe}}}{100 \mathrm{~A}_{\mathrm{Ti}}}=\frac{55.847 w[\mathrm{Ti}]_{\gamma}}{4790}
$$

The semi-coherent grain boundary energy between $\mathrm{TiC}, \mathrm{TiN}$ and $\gamma$ can be calculated by formula (18) and (19) [14]. The semi-coherent grain boundary energy between $\operatorname{Ti}\left(\mathrm{C}_{x} \mathrm{~N}_{1-x}\right)$ and $\gamma$ can also be obtained by linear interpolation. Then the coarsening rate coefficient of $\mathrm{Ti}\left(\mathrm{C}_{x} \mathrm{~N}_{1-x}\right)$ canbe calculated by the above formulas.

$$
\begin{aligned}
\sigma_{\mathrm{TiC}-\gamma}\left(\mathrm{J} / \mathrm{m}^{2}\right) & =0.9304-0.4156 \times 10^{-3} T(\mathrm{~K}) \\
\sigma_{\mathrm{TiN}-\gamma}\left(\mathrm{J} / \mathrm{m}^{2}\right) & =0.8737-0.3902 \times 10^{-3} T(\mathrm{~K})
\end{aligned}
$$

Because the titanium inclusions in the steel slab which taken from the actual production field is very few. In order to be convenient for statistical analysis, the $82 \mathrm{~A}$ steel slab was remelted in the $25 \mathrm{~kg}$ vacuum furnace under nitrogen atmosphere, and a certain amount of titanium sponge were added in the remelting process, then the molten steel containing high Ti and $\mathrm{N}$ was cast into ingot. The composition of the steel sample is shown in Table 1 .

According to the front theoretical analysis, the solid solution of $\mathrm{C}, \mathrm{N}, \mathrm{Ti}$ and coarsening rate coefficient $(m)$ at different temperature can be calculated, as shown in Table 2.

Table 2 shows that in the range of $1100^{\circ} \mathrm{C}$ to $1250^{\circ} \mathrm{C}$, The carbon is virtually all solid solution, little change with temperature. The solution quantity of Ti and $\mathrm{N}$ increased as the temperature rises. The increased amount of solid 
Table 1. The composition of specimen (\%).

\begin{tabular}{ccccccccc}
\hline Sample steel & $\mathrm{C}$ & $\mathrm{Si}$ & $\mathrm{Mn}$ & $\mathrm{P}$ & $\mathrm{S}$ & $\mathrm{Ti}$ & $\mathrm{N}$ & T.O \\
\hline $82 \mathrm{~A}$ & 0.80 & 0.18 & 0.53 & 0.019 & 0.0064 & 0.055 & 0.0167 & 0.0037 \\
\hline
\end{tabular}

Table 2. The solid solution quantity and coarsening rate of specimen at different temperature.

\begin{tabular}{cccccc}
\hline Temperature & $W[\mathrm{Ti}]_{\gamma}$ & $W[\mathrm{~N}]_{\gamma}$ & $w[\mathrm{C}]_{\gamma}$ & $\mathrm{m} /\left(\mathrm{nm} / \mathrm{s}^{1 / 3}\right)$ & ${ }_{\mathrm{Ti}} /\left(\mathrm{cm}^{2} / \mathrm{s}\right)$ \\
\hline 1100 & 0.00083 & 0.00322 & 0.7980 & 0.4826 & $4.24 \times 10^{-11}$ \\
1150 & 0.00126 & 0.00336 & 0.7980 & 0.6973 & $9.19 \times 10^{-11}$ \\
1200 & 0.00187 & 0.00353 & 0.7980 & 0.9775 & $1.89 \times 10^{-11}$ \\
1250 & 0.00267 & 0.00372 & 0.7980 & 1.3323 & $3.70 \times 10^{-10}$ \\
\hline
\end{tabular}

solution is implemented by the decomposition of the titanium inclusions. At the condition of high temperature, the titanium inclusions have two process of solid solution and coarsening at the same time, combined with the Ostwald ripening process of titanium inclusions. Therefore, the diffusion and interfacial reaction control the Ostwald ripening process for the large titanium inclusions.

Among them, the diffusion of titanium is the restrictive step for the decomposition and growth of titanium inclusion. In addition, the diffusion coefficient of titanium in austenite is still very small in the range of heating temperature, which can be seen from Table 2. The theoretical calculation results show that the coarsening rate of titanium carbonitride particle is very small, when the temperature is $1100^{\circ} \mathrm{C}$, the coarsening rate of titanium carbonitride coarsening rate is only $0.4826 \mathrm{~nm} / \mathrm{s}^{1 / 3}$. The coarsening rate of titanium carbonitride are all less than $1 \mathrm{~nm} / \mathrm{s}^{1 / 3}$, when the temperatures are below $1200^{\circ} \mathrm{C}$, even if the holding time is $6 \mathrm{~h}$, the value of $m t^{1 / 3}$ are also less than $28 \mathrm{~nm}$. When the heating temperature is $1250^{\circ} \mathrm{C}$ and holding for $6 \mathrm{~h}$, the value of $m t^{1 / 3}$ is only $37 \mathrm{~nm}$. For the actual content level of $\mathrm{Ti}$ and $\mathrm{N}$, the coarsening rate of titanium carbonitride when holding at high temperature will be smaller. Therefore, for the titanium carbonitride phase at high temperature, the coarsening behavior can be completely ignored. This is the important reason why the titanium carbonitride is used to control the austenite grain coarsening in some micro titanium steels [15] [16].

After high temperature heating, the balanced solid solubility product of $\mathrm{Ti}, \mathrm{N}$ elements in the austenite will be decreased in the subsequent rapid cooling process. When the balanced solid solubility product is less than the actual solid solubility product, the $\mathrm{Ti}$ and $\mathrm{N}$ which in the state of solid solution will re-precipitate. Due to the rapid cooling rate, the Ti and $\mathrm{N}$ atoms which closer to the incomplete decomposed titanium inclusion will take it as the precipitation nucleation and grow up, the rest of the distant $\mathrm{Ti}, \mathrm{N}$ atoms which in the state of supersaturation will precipitate in homogeneous nucleation and don't have a chance to grow up or keep the supersaturated state. 


\section{Confocal Laser Scanning Microscopy Analysis}

\subsection{Main Experimental Equipment}

The confocal laser scanning microscopy (CLSM) canbe used to in-situ observe the phase change, solidification, crystallization and other details of steel samples at high temperature conditions. In order to directly observe the solid solution behavior of single titanium inclusion in heating and holding process. The specimen is analyzed by CLSM. The main experimental equipment is shown in Figure 1 .

\subsection{Experimental Methods}

Specific experimental methods are as follows:

1) The steel sample in Table 1 was made into the metallographic specimen of size $\varphi 6 \mathrm{~mm} \times 4 \mathrm{~mm}$, and the possible titanium inclusions were found by the metallographic microscope and marked.

2) Then to confirm whether the marked ones were titanium inclusions by SEM.

3) The sample was cleaned by ultrasonic wave for $1 \mathrm{~min}$, then the specimen was put into a small crucible, and the crucible was placed on the Pt scaffold. After inspecting the experimental equipment, vacuumized the furnace to $10^{-2} \mathrm{~Pa}$ and then filled with the high purity Ar.

4) The heating rate was $150 \mathrm{~K} / \mathrm{min}$, heated to the temperature of $1300^{\circ} \mathrm{C}$ and holding for $20 \mathrm{~min}$, then cooled to room temperature at the rate of $300 \mathrm{~K} / \mathrm{min}$.

\subsection{In-Situ Observation and Analysis of Titanium Inclusion}

The morphology of titanium inclusions at room temperature, $800^{\circ} \mathrm{C}, 1100^{\circ} \mathrm{C}$, $1300^{\circ} \mathrm{C}$ holding for $0-20 \mathrm{~min}$ and cooled to $300^{\circ} \mathrm{C}$ were shown in Figure 2 .

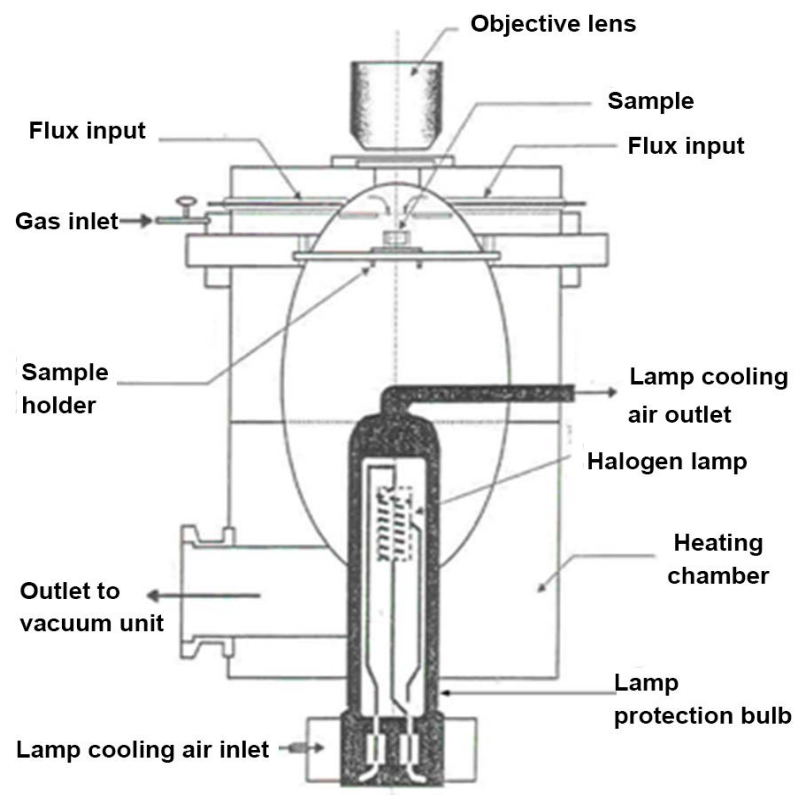

Figure 1. Confocal laser scanning microscopy. 

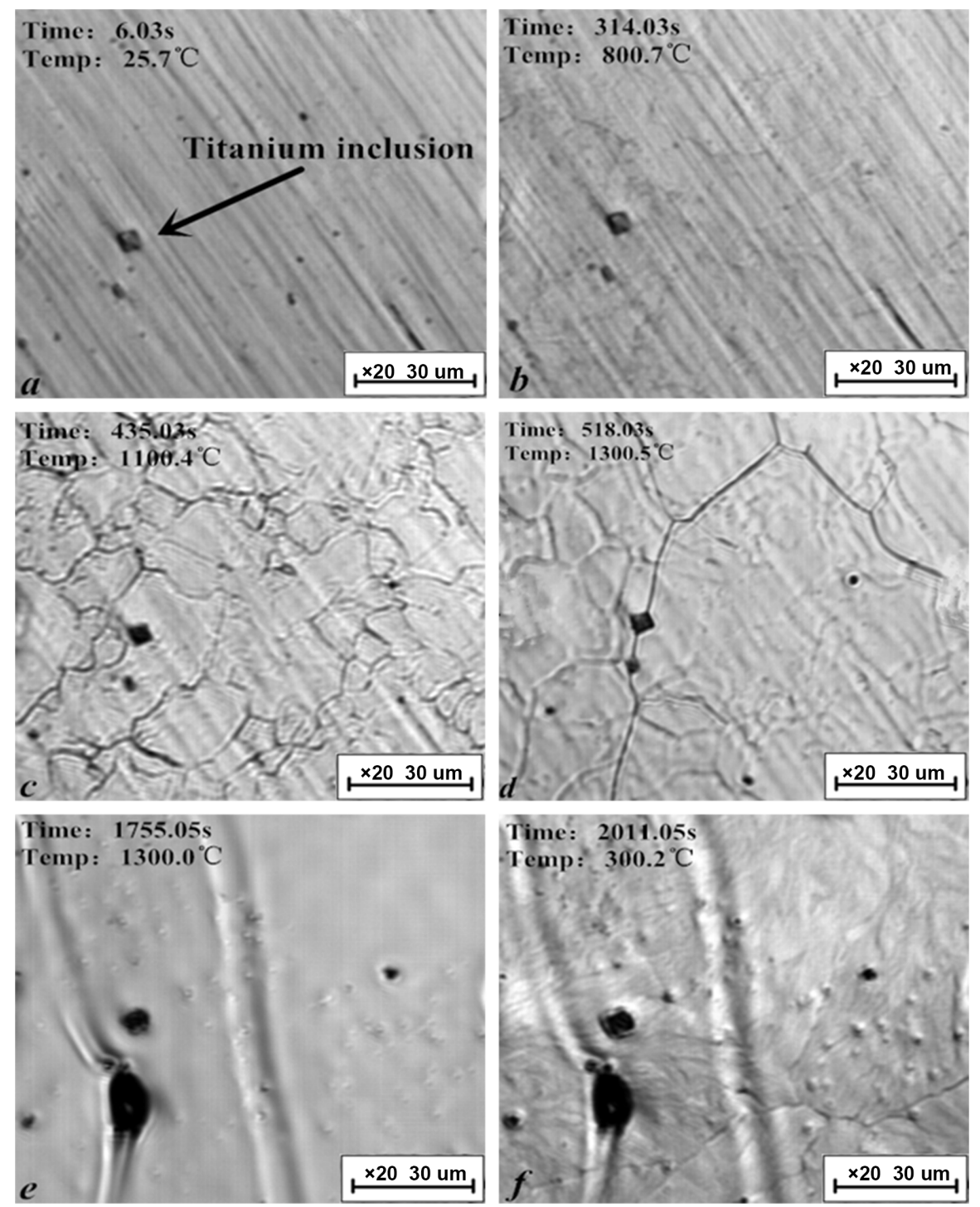

Figure 2. The morphology of titanium inclusion at different time and temperature.

As can be seen from the Figure 2, the texture and phase of specimen from room temperature to $1300^{\circ} \mathrm{C}$ were changed obviously. However, the morphology of titanium inclusion was not changed significantly, and the outline was still relatively clear (as shown in Figures 2(a)-(d)). When holding for $20 \mathrm{~min}$ (as shown in Figure 2(e)), It can be seen that the titanium inclusion was no longer clear, the outline of the edge became more pliable, and a small light area appeared around the titanium inclusion, its morphology has changed compared with before. After cooling to $300^{\circ} \mathrm{C}$, as shown in Figure 2(f), the central color of titanium inclusion was deeper, and the surrounding area was light. The light color of the surrounding area was most likely caused by the solid solution behavior of titanium inclusion. Due to the rapid cooling rate $(300 \mathrm{~K} / \mathrm{min})$, the titanium inclusion which partly dissolved was too late to re-precipitate and grow up, thus appeared the morphology shown in Figure 2(f). The influence factors of solid solution behavior for titanium inclusion in tire cord steel during the heating 
process will be explored in the further work.

\section{Conclusions}

Based on the thermodynamic theory analysis and CLSM experiment, the solid solution behavior of titanium inclusion in tire cord steel during the heating process was studied. The conclusions are as follows:

1) According to the law of Ostwald repening, the coarsening rate of titanium carbonitride inclusion is very small, the coarsening behavior of titanium carbonitride inclusion cannot be considered in the heating and holding stage.

2) The solid solution behavior of titanium inclusion in the heating process is obviously existed.

3) Through the proper control of rolling temperature, holding time and the subsequent cooling rate, the size and quantity of large particle titanium inclusion in the high strength tire cord steel can be effectively controlled.

\section{Acknowledgements}

The author gratefully acknowledges the financial support by the National Natural Science Foundation of China (Grant No. 51704105).

\section{References}

[1] Cui, H.Z., Chen, W.Q. and Mao, W.M. (2011) Effects of Rolling Processes on Textures of Wires for Tire Cord Steel. Journal of University of Science and Technology Beijing, 33, 947-951.

[2] Michelic, S.K., Loder, D. and Reip, T. (2015) Characterization of TiN, TiC and $\mathrm{Ti}(\mathrm{C}, \mathrm{N})$ in Titanium-Alloyed Ferritic Chromium Steels Focusing on the Significance of Different Particle Morphologies. Materials Characterization, 100, 61-67. https://doi.org/10.1016/j.matchar.2014.12.014

[3] Xue, Z.L., Jin, W.T. and Lei, J.L. (2016) Precipitation and Control of Titanium Inclusions in Tire Cord Steel Production. Steelmaking, 32, 23-32.

[4] Liu, H.Y., Wan, B.Y. and Zeng, X.Y. (2015) Effect of V and N on Microstructures and Properties of Grade-70 Tire Cord Steel during Cold Drawing. Journal of Iron \& Steel Research International, 22, 171-178. https://doi.org/10.1016/S1006-706X(15)60026-7

[5] Shi, L., Hong, J. and Li, X.M. (2014) Control of Titanium Inclusions in Tire Cord Steel. Research on Iron \& Steel, 42, 50-52.

[6] Chang, H.W. and Zhang, Z.Z. (2014) Technology for Controlling Content of Total Oxygen in Wire Rod for Cord Steel. Aisc Techniques, 2, 17-19.

[7] Wang, R.M., Gui, J.B. and Ren, A.C. (2015) Actual Product Quality Comparison Analysis of Domestic and Overseas Tire Cord Steel Wire Rod. Metal Products, 41, 49-53.

[8] Tang, W., Guo, J.L. and Wang, M. (2016) Fracture Form and Cause Analysis of 82A Tire Cord Steel. Metal Materials and Metallurgy Engineering, 6, 9-12.

[9] Yong, Q.L., Liu, Z.D. and Sun, X.J. (2005) Theoretical Calculation for Equilibrium Solubilities and Compositional Coefficient of Titanium Carbonitrides in Ti-Bearing Microalloyed Steel. Iron Steel Vanadium Titanium, 26, 12-16. 
[10] Hudd, R.C., Jones, A. and Kale, M.N. (1971) A Method for Calculating the Solubility and Composition of Carbonitride Precipitates in Steel with Particular Reference to Niobium Carbonitride. JISI, 209, 121-125.

[11] Zhang, J., Xue, Z.L. and Jiang, Y.D. (2014) Solid Solution of Ti Inclusions during Heating Process for Cast Bloom of Tire Cord Steel SWRH82A. Journal of Materials and Metallurgy, 13, 242-246.

[12] Lifshitz, I.M. and Slyozov, V.V. (1961) The Kinetics of Precipitation from Supersaturated Solid Solutions. Journal of Physics and Chemistry of Solids, 19, 35-50. https://doi.org/10.1016/0022-3697(61)90054-3

[13] Maugis, P. and Goune, M. (2005) Kinetics of Vanadium Carbonitride Precipitation in Steel: A Computer Model. Acta Materialia, 53, 3359-3367. https://doi.org/10.1016/j.actamat.2005.03.036

[14] Yong, Q.L., Li, Y.F. and Sun, Z.B. (1989) Theoretical Calculation of Specific Interfacial Energy of Semicoherent Interface between Microalloy Carbonitrides and Austenite. Acta Metallurgica Sinica, 2, 153-156.

[15] Zheng, Y.F., Li, X.C. and Wu, R.M. (2017) Influence of Ti on Grain Growth Behavior of Non-Quenched and Tempered Plastic Mold Steel. Materials Review, 31, 82-87.

[16] Hui, Y.J., Yu, Y. and Wang, C. (2014) Austenite Grain Coarsening Behavior of Titanium Microalloyed High Strength Steel. Transactions of Materials and Heat Treatment, 35, 140-145. 